\title{
Para desarticular os estratos dominantes do organismo, da significância e da subjetivação
}

\author{
Dislocating the dominant stratums of the organism, significance \\ and subjectification
}

\author{
Juliana Martins Rodrigues ${ }^{[a]}$, Carlos Augusto Peixoto Júnior ${ }^{[b]}$
}

[a] Mestre em Psicologia Clínica pela Pontifícia Universidade Católica do Rio de Janeiro (PUC-Rio), Rio de Janeiro, RJ - Brasil, e-mail: julianamartinspsi@hotmail.com

[b] Psicanalista, Doutor em Saúde Coletiva pela Universidade Federal do Rio de Janeiro (IMS/UERJ), professor do programa de Pós-Graduação em Psicologia Clínica da Pontifícia Universidade Católica do Rio de Janeiro (PUC-Rio), Pesquisador do CNPq, Rio de janeiro, RJ - Brasil

\section{Resumo}

O presente artigo tem como objetivo abordar os três principais estratos a que estamos mais diretamente submetidos em nossa cultura, a saber: o organismo, a significância e a subjetivação, tais como definidos por Deleuze e Guattari em Mil Platôs. Os autores indicam que é preciso deslocar a ênfase desse conjunto de estratos molares para um novo foco: ao invés do sujeito fixado a representações transcendentes, que deve ser intérprete e é interpretado com seus "significados secretos", e que vê seu corpo submetido a se apresentar como um organismo organizado de acordo com modelos normatizados, devemos nos voltar para a vida e seu processo de atualização, que não pode ficar restrito a limites tão estreitos e estanques. Pretende-se apontar a forma como a psicanálise mais tradicional participa mais de uma política de limitação do que de libertação de tais estratos, ao vincular o inconsciente à necessidade da interpretação e ao acorrentar a tradução do desejo às estruturas do Édipo e da castração, desconsiderando, assim, a singularidade das experiências existenciais e a multiplicidade de sentidos que elas podem ter. Por meio da análise da desarticulação dos estratos proposta pelos autores, poderão ser percebidas novas possibilidades, mapas e percursos desidentificados, encontrados, por exemplo, no discurso das crianças, em que se pode notar que o transcendente é substituído pelo transcendental.

Palavras-chave: Estratos. Desarticulação. Corpo sem órgãos. Devir. Hecceidade. 


\begin{abstract}
The present article aims to discuss the three main stratums to which we are mostly submitted in our culture, namely the body, the significance and the subjectification as defined by Deleuze and Guattari in A Thousand Plateaus. The authors suggest that we must shift the emphasis from this molar stratums to a new focus: instead of the subject set to transcendental representations, that needs to be an interpreter and is also interpreted with their "secret meanings", with their body having to present itself as an organized body according to standardized models, we should direct our attention to life and its updating process, which cannot be restricted to limits so narrow and tight. We intend to point out the way in which classical psychoanalysis takes part in a policy of limitations more than of liberation of these stratums, by linking the unconscious to the need of interpretation and by submitting the translation of desire to the structures of Oedipus and castration, without considering the singularity of the existential experiences and the multiplicity of meanings that they can have. Through the analysis of the dislocation of the stratums proposed by the authors, it will be possible to realize new opportunities, maps and unidentified routes that can be found, for example, in the speech of children, where we can see that the transcendent is replaced by the transcendental.
\end{abstract}

Keywords: Stratum. Dislocation. Body without organs. Becoming. Haecceity.

Para Deleuze e Guattari ([1980] 1996), os três grandes estratos que nos amarram mais diretamente à cultura estabelecida são os do organismo, da significância e da subjetivação. A dimensão do organismo pretende que sejamos organizados e tenhamos um corpo articulado. Caso contrário, seremos apenas marginais depravados ou cópias imperfeitas de modelos normatizados. No estrato da significância, deveremos ser significantes e significados, intérpretes e interpretados, senão, mais uma vez, seremos desviantes. No ponto da subjetivação ou sujeição, seremos sujeitos e, enquanto tais, fixados às representações transcendentes que organizam o modo dominante de produção de subjetividades.

Os autores ressaltam que é preciso deslocar a ênfase desse conjunto de estratos molares (o sujeito, seus "significados secretos" e seu organismo) para a vida e seu processo de atualização, o qual não poderia ficar restrito a limites tão estreitos e estanques. Eles consideram, portanto, que é preciso desarticular tais estratos, realizando experimentações sobre um plano de consistência, dado que a subjetividade seria prioritariamente nômade, e não exclusivamente fixa. Trata-se aqui de um confronto entre a produção e a representação, que ressalta a importância do pré-individual, do parcial, e de um processo livre do pensamento da representação que insiste em impor formas universais e cristalizadas a tudo o que implica diferença e singularidade.

O pensamento da representação, ao qual Deleuze e Guattari se opõem, não suporta a diferença e busca um princípio de recognição, de "devir semelhante" para todas as coisas. Tudo o que aí não se encaixa cai num plano indiferenciado, uma espécie de "buraco negro" que passa a ser ignorado ou marginalizado em virtude de sua singular potência de fuga diante dos padrões estabelecidos. A desarticulação desses estratos dominantes de nossa cultura é positivada e incentivada por Deleuze e Guattari, que propõem a dissolução do sujeito, do ser sujeitado a categorias universais ditadas a priori.

Deleuze e Guattari criam um sistema aberto às multiplicidades e às estratégias de resistência a modos de produção de subjetividade reativa. Com isso, buscam introduzir um movimento no pensamento que, ao retirá-lo de sua imobilidade, rompe com os pressupostos da representação e enfatiza a diferença. Para desarticular o corpo, os autores elaboram o conceito de corpo sem órgãos; contra a interpretação, propõem a experimentação; contra a sujeição, optam pelo que desfaz a organização imposta aos corpos, descobrindo outras populações e outras zonas que os habitam.

Analisaremos, primeiramente, a proposta de desarticulação do organismo que os autores empreendem com a ideia de corpo sem órgãos. Esse conceito possibilita uma crítica à noção de organização, ao corpo como organismo organizado, à estratificação e à rigidez representacional do corpo, e propõe pensar uma dimensão de caos relativo que se opõe à ordem. Portanto, é importante ressaltar que não se trata de caos total, e sim de um corpo entendido 
como espaço intensivo, mais flexível, amplo e aberto, possibilitando a passagem de fluxos e intensidades. Enfim, o corpo como espaço real, sem o aprisionamento da representação. Os órgãos não desaparecem, apenas ganham um papel mais maleável, voltam a um estado do corpo anterior à organização orgânica, ao organismo que lhes aprisionou a vida. Segundo Eugene Holland (1999), Deleuze e Guattari recorrem a esse termo de Artaud ([1948] 2004) para levantar a questão de como o corpo é organizado e como ele pode ser ativamente desorganizado para permitir a produção de outras formas de organizações não fixadas, como por exemplo, na esquizofrenia. O corpo sem órgãos é o corpo se apresentando como um campo de afetos.

Os autores dizem que, de qualquer forma, tem-se um ou vários $\mathrm{CsO}$ (corpo sem órgãos), que não se pode desejar sem construí-lo, que se trata de uma experimentação inevitável, e que estamos sobre ele: esse é o lugar onde dormimos, desejamos, lutamos, fracassamos. Não se chega ao corpo sem órgãos porque já estamos sobre ele, o que não é tranquilizador visto que podemos falhar e construir agenciamentos que nos levem à morte.

"No dia 28 de novembro de 1947, Artaud declara guerra aos órgãos" (Deleuze \& Guattari, [1980] 1996, p. 10). Para os autores de Mil Platôs, o Cso está a caminho desde que o corpo se cansou dos órgãos e os quer perder - desde o corpo hipocondríaco, que sente ter órgãos destruídos, embora nada esteja errado com a sua saúde, até o corpo esquizo, que desenvolve uma luta ativa contra os órgãos chegando mesmo à catatonia.

Mas por que esse desfile lúgubre de corpos costurados, vitrificados, catatonizados, aspirados, posto que o CsO é também pleno de energia, de êxtase, de dança? Então, por que esses exemplos? Por que énecessário passar por eles? Corpos esvaziados em lugar de plenos. Que conteceu? Você agiu com a prudência necessária? Não digo sabedoria, mas prudência como dose, como regra imanente à experimentação: injeções de prudência. Muitos são derrotados nessa batalha. Será tão triste e perigoso não mais suportar os olhos para ver, os pulmões para respirar, a boca para engolir, a língua para falar, o cérebro para pensar, o ânus e a laringe, a cabeça e as pernas? Por que não caminhar com a cabeça, cantar com o sinus, ver com a pele, respirar com o ventre, coisas simples, entidade, corpo pleno, viagem imóvel, anorexia, visão cutânea, Yoga, Krishna, love, experimentação. Onde a psicanálise diz: pare, reencontre o seu eu, seria preciso dizer: vamos mais longe, não encontramos ainda nosso $\mathrm{CsO}$, não desfizemos ainda suficientemente nosso eu. Substituir a anamnese pelo esquecimento, a interpretação pela experimentação. Encontre seu corpo sem órgãos, saiba fazê-lo, é uma questão de vida ou de morte, de juventude e de velhice, de tristeza e de alegria. É aí que tudo se decide (Deleuze \& Guattari, [1980] 1996, p. 11).

Para cada tipo de $\mathrm{CsO}$ deve-se perguntar de que tipo se trata, como é fabricado, quais são seus modos, o que acontece, com que variantes - deve-se fazer uma análise infinita sobre aquilo que é produzido sobre ele. Os autores consideram que o $\mathrm{CsO}$ é, e deve ser, uma experimentação muito delicada, porque não pode haver estagnação dos modos nem construções que constantemente tangenciem perigos e o esvaziem em vez de preenchê-lo. Pode-se criar um $\mathrm{CsO}$ escolhido como um bom lugar e, no entanto, alguma coisa pode impedir a circulação das intensidades, pode existir um ponto de bloqueio pelo qual nada passa. Bloquear - e ser bloqueado - é ainda uma intensidade, mas o importante em cada caso é definir o que faz passar e o que impede a passagem de intensidades.

Para os autores, o organismo não seria um corpo, mas um estrato sobre o CsO, um fenômeno de coagulação, de sedimentação que lhe impõe formas, funções e organizações dominantes e hierarquizadas, transcendências organizadas para extrair um trabalho útil. Não paramos de ser estratificados, e o CsO é a realidade sobre a qual vão se formar coagulações que compõem um organismo, acompanhado também de uma significação e de um sujeito.

O Cso grita: fizeram-me um organismo! Dobraram-me indevidamente! Roubaram meu corpo! O juízo de Deus arranca-o de sua imanência, e lhe constrói um organismo, uma significação, um sujeito. É ele o estratificado. Assim, ele oscila entre dois pólos: de um lado, as superfícies de estratificação sobre as quais ele é rebaixado e submetido ao juízo, e, por outro lado, o plano de consistência no qual ele se desenrola e se abre à experimentação. E se 
o CsO é um limite, se não se termina nunca de chegar a ele, é porque há sempre um estrato atrás de um outro estrato, um estrato engastado em outro estrato. Porque são necessários muitos estratos e não somente o organismo para fazer o juízo de Deus. Combate perpétuo e violento entre o plano de consistência, que libera o $\mathrm{CsO}$, atravessa e desfaz todos os estratos, e as superfícies de estratificação que o bloqueiam ou rebaixam (Deleuze \& Guattari, [1980] 1996, p. 21-22).

Desarticular o organismo, desfazê-lo, significa abrir o corpo a novas experimentações, agenciamentos, múltiplas articulações, conjunções, sem que isso leve à morte ou ao suicídio. Não podemos confundir movimentos de autodestruição, implícitos na visão freudiana da pulsão de morte, com a visão deleuziana da pulsão de morte, que fala de um movimento de libertação de conteúdos prévios com o objetivo de criar novos agenciamentos, habitar novas terras.

Segundo os autores, desfazer o organismo não é mais fácil do que desfazer os outros estratos dominantes de nossa cultura, o da significância ou o da subjetivação. A noção de significância, impregnada em nossa forma de pensar, impede que o inconsciente se liberte da interpretação e possa se tornar uma verdadeira produção. Já o conceito de sujeito teima em nos fixar a uma realidade dominante e nos impede de fazer da consciência um meio de exploração. Porém, para realizar essa desarticulação dos estratos dominantes, a prudência se faz necessária nos três casos.

Um movimento muito violento de liberação dos estratos, sem a prudência necessária, traz a catástrofe, entradas sem saídas, em vez de traçar um plano. "O pior não é permanecer estratificado organizado, significado, sujeitado - mas precipitar os estratos numa queda suicida ou demente, que os faz recair sobre nós, mais pesados do que nunca" (Deleuze \& Guattari, [1980] 1996, p. 23-24).

Para construir um plano de composição, é necessário instalar-se sobre um estrato, experimentar o que ele tem a oferecer, buscar dentro dele espaços favoráveis, linhas de fuga possíveis, movimentos de desterritorialização, enfim, ter sempre em vista um pedaço de uma nova terra. É dessa forma que o $\mathrm{CsO}$ se revela pelo que é: conexão de desejos, conjunção de fluxos, puras intensidades, pequena máquina privada pronta para ramificar-se em outras máquinas coletivas.

Há desejo toda vez que há constituição de um $\mathrm{CsO}$, e existem desejos de todos os tipos desejo fascista, desejo de dinheiro, etc. É a partir disso que Deleuze e Guattari propõem que uma análise deve se preocupar em saber se possuímos os meios de realizar a seleção que separa o $\mathrm{CsO}$ de corpos vazios, cancerosos, totalitários. O que importa não é denunciar falsos desejos, até porque estes não existem. Importante é saber distinguir o que remete à proliferação de estratos ou à desestratificação violenta, e o que remete à construção do plano de consistência.

Para os autores, a psicanálise mais tradicional perdeu o contato com o real porque se distanciou excessivamente do $\mathrm{CsO}$ ao traduzir tudo em fantasmas, significâncias e subjetivações. O Cso é o real, o que resta quando tudo foi retirado.

Deleuze e Guattari acreditam nos devires moleculares que minam as grandes potências molares, como o corpo organizado, a família, a profissão e a conjugalidade. Eles preferem pensar a partir de uma corrente alternativa, de uma circulação de afetos impessoais que tumultua os projetos significantes e os sentimentos subjetivos, constituindo uma irresistível desterritorialização que anula de antemão as tentativas de reterritorialização edipiana, conjugal ou profissional. Os autores pensam em termos de devires: devir-intenso, devir-imperceptível, devir-animal, devir-mulher.

Passemos então para as proposições dos autores acerca do devir. Para eles, assim como um devir não é uma correspondência de relações, ele também não é uma semelhança, uma imitação ou uma identificação. $\mathrm{O}$ devir não produz outra coisa senão ele próprio. A alternativa que nos faz dizer que ou imitamos ou somos alguma coisa é falsa. "O que é real é o próprio devir, o bloco de devir, e não os termos supostamente fixos pelos quais passaria aquele que se torna" (Deleuze \& Guattari, [1980] 1997, p. 18). O devir é da ordem da aliança e não da filiação. O devir é feito de rizoma, não de árvores genealógicas.

Segundo os autores, a psicanálise ortodoxa encontrou frequentemente a questão dos devires-animais do homem na criança e, sobretudo, no masoquismo. No entanto, a psicanálise mais tradicional massacrou o devir-animal no homem e na 
criança. Limitou-se a ver no animal um representante das pulsões ou uma representação dos pais. Para os autores, esta psicanálise não conhece os agenciamentos que uma criança pode montar para resolver um problema cujas saídas lhe estão sendo barradas; as crianças constroem um plano, e não um fantasma.

O plano de imanência fracassa quando um outro plano volta à força e, mais uma vez, só reconhece semelhanças entre elementos e analogias entre relações. O plano de consistência, em vez de reduzir a dois o número de dimensões das multiplicidades, recorta-as todas para fazer coexistirem outras tantas multiplicidades planas com dimensões quaisquer. O plano de imanência é a máquina abstrata na qual cada agenciamento é uma multiplicidade, um devir. Uma intensidade é um indivíduo, uma hecceidade, uma individuação sem sujeito. Tudo se torna imperceptível, tudo é devir-imperceptível no plano de consistência, mas é justamente nele que o imperceptível é visto ou ouvido.

O devir é um processo do desejo, princípio de aproximação que indica o mais rigorosamente possível uma zona de vizinhança ou de copresença de uma partícula. Dessa forma, todos os devires são moleculares - coletividades moleculares, hecceidades, e não sujeitos molares que conhecemos fora de nós. Há um devir-mulher, um devir-criança, que não se parecem com a mulher ou com a criança como entidades molares distintas. Por entidade molar, podemos entender aqui, por exemplo, a mulher percebida a partir de uma dualidade que a opõe ao homem como determinada por sua forma, marcada como sujeito. O devir-mulher não é, definitivamente, imitar essa entidade, transformar-se nela, mas sim emitir partículas que entrem na zona de vizinhança de uma micro-feminilidade, produzir em nós mesmos uma mulher molecular. Os autores consideram que também não basta fazer como a psicanálise clássica e falar de uma bissexualidade, na qual cada sexo contém o outro e deve desenvolver em si mesmo o seu polo oposto; isso seria interiorizar a máquina binária, e não sair da lógica dual.

Para Deleuze e Guattari, todos os devires começam e passam pelo devir-mulher, que é a chave de todos os outros devires. Isso porque é da menina, primeiro, que se rouba o corpo, com advertências do tipo: "pare de se comportar assim" ou "você não é um moleque". É dela que se rouba seu devir para impor-lhe uma história, ou uma pré-história. O menino vem logo depois. É-lhe mostrado o exemplo da menina, indicando-a como objeto de seu desejo, um organismo oposto. Exatamente por ser a menina a primeira vítima, que, inversamente, a reconstrução do corpo como corpo sem órgãos é inseparável do devir-mulher.

Os autores afirmam que, apesar de tantos devires do homem, não há um devir-homem. Isso acontece pelo fato de que o homem é majoritário por excelência, enquanto os devires são minoritários. Por maioria, entende-se aqui a determinação de um estado ou de um padrão em relação ao qual tanto as quantidades maiores quanto as menores serão ditas minoritárias. O padrão molar-majoritário aqui considerado é o do homem branco, adulto, macho, razoável, etc. É nesse sentido que as mulheres, as crianças, os animais, os vegetais, as moléculas são minoritários. Enfim, não há devir-homem, porque o homem é a entidade molar por excelência, enquanto os devires são moleculares.

Seguindo-se ao devir-mulher, passa-se pelos devires-animais, e por todos os outros devires que se precipitam em direção a um devir-imperceptível.

O devir-imperceptível quer dizer muitas coisas: primeiramente, quer dizer ser como todo mundo, não se fazer notar, ser desconhecido. Segundo os autores, isso não é nada fácil, já que não é todo mundo que se torna todo mundo, ou seja, não é todo mundo que se caracteriza como um devir.

Pois todo mundo é o conjunto molar, mas devir todo mundo é outro caso, que põe em jogo o cosmo com seus componentes moleculares. Devir todo mundo é fazer mundo, fazer um mundo. À força de eliminar, não somos mais do que uma linha abstrata, ou uma peça de quebra-cabeça em si mesma abstrata. É conjugando, continuando com outras linhas, outras peças que se faz um mundo, que poderia recobrir o primeiro, como em transparência. A elegância animal, o peixe camuflador, o clandestino: ele é percorrido por linhas abstratas que não se parecem com nada, e que não seguem nem mesmo suas divisões orgânicas; mas, assim desorganizado, desarticulado, ele faz mundo com as linhas de um rochedo, da areia e das plantas, para devir imperceptível (Deleuze \& Guattari, [1980] 1997, p. 73).

Para os autores, o movimento, os devires estão numa relação essencial com o imperceptível - 
Rodrigues, J. M., \& Peixoto Jr., C. A.

são por natureza imperceptíveis, por serem puras relações de velocidade e lentidão, puros afetos que estão abaixo ou acima do limiar de percepção. Os devires são imperceptíveis, pelo menos num plano que dá formas a serem percebidas, como no plano de transcendência. $O$ imperceptível só pode ser percebido no plano de imanência, onde o próprio princípio de composição deve ser percebido. É a diferença dos dois planos que faz com que aquilo que não pode ser percebido num deles só possa ser percebido no outro. No plano de imanência, a percepção não está mais na relação entre um sujeito e um objeto, mas no movimento que está associado a essa relação: a percepção está entre as coisas, apenas os movimentos são olhados. Nesse plano, o próprio imperceptível torna-se necessariamente percebido, ao mesmo tempo em que a percepção torna-se necessariamente molecular.

Para Deleuze e Guattari ([1980] 1997), o inconsciente - que na psicanálise poderia dar conta do imperceptível e dos fenômenos afetivos permanece como um plano de transcendência que deve justificar a existência do psicanalista e a necessidade de suas interpretações. Uma vez que o desejo deve ser traduzido para esse plano, ele acaba acorrentado a molaridades, como a estrutura do Édipo e a castração.

De acordo com os autores, a psicanálise clássica deu ao inconsciente a pesada incumbência de ser, ele próprio, a forma infinita do segredo que torna necessário todo um trabalho para medir seus conteúdos a partir de uma forma pura. Quando o "segredo" se revela em termos de Edipo, falo e castração, isso se traduz em absolutamente nada, tudo isso se torna risível.

Os autores afirmam que não se rompe com o esquema de arborescência, não se atinge o devir, nem o molecular, enquanto uma linha for remetida a um ponto. O devir é um movimento pelo qual a linha se libera do ponto, e torna os pontos indiscerníveis, rizoma que se livra da arborescência. Um sistema é pontual enquanto as linhas forem consideradas nele como coordenadas, ou como ligações localizáveis. O que se opõe ao sistema pontual são sistemas lineares ou, antes, multilineares. No caso da psicanálise mais tradicional, pode-se aceitar as suas linhas e diretrizes principais, como as territorialidades edipianas, a primazia do falo e toda a problemática da castração. A questão é não permitir que a teoria se feche apenas nisso e dessa forma não reconheça outras tantas possibilidades de "verdades" mutantes, as diversas outras linhas que surgem das multiplicidades que as relações compõem e que não remetem a um ponto de origem, posto que podem nascer de um meio não-localizável. Deleuze e Guattari consideram que um sistema pontual será mais interessante à medida que um músico, um escritor, um filósofo, ou até mesmo um psicanalista se oponha a ele, fabricando-o como um trampolim para saltar e alcançar uma multiplicidade de pontos de vista.

Nesse sentido, o território é visto como um lugar de passagem, e caberia ressaltar os meios que o atravessam. Todo agenciamento é territorial e, em muitos casos, constata-se uma formação de novos agenciamentos no agenciamento territorial, uma abertura inovadora, uma função agenciada, territorializada, que adquire independência suficiente para formar ela própria um novo agenciamento em vias de desterritorializacão. Logo, o território não para de ser percorrido por movimentos de desterritorialização relativa. Diante disso, podemos dizer que a psicanálise não pode mais esperar que as pessoas simplesmente se submetam a uma relação analítica reproduzindo histórias e comportamentos universais dados a priori, e deixando de lado todo um aspecto criativo relacionado a novos agenciamentos que fazem com que elas se movam por caminhos singulares.

A vida é um sistema de estratificação complexo e, ao mesmo tempo, um conjunto de consistência, coexistências, que perturba as ordens e as formas. Para Deleuze e Guattari, a vida não se contenta com a função de resolver meios, mas sim agenciar territórios. A psicanálise precisa estar aberta a esses movimentos vitais, ao invés de se fechar e se defender com uma teoria imutável.

A questão agora gira em torno da consistência ou da consolidação. Como tornar um material consistente a ponto de ele poder captar forças não-sonoras, não-visíveis, não-pensáveis? Deleuze e Guattari declaram que saímos da época dos agenciamentos para entrar na idade da máquina, de uma imensa mecanosfera, plano das forças a serem captadas.

A máquina, assim como o devir, se apresenta de forma diferente em cada agenciamento. Ela passa de um para outro, abre um para o outro, independentemente de uma ordem fixa. Nesses termos, quando procura domesticar o 
inconsciente maquínico, a teoria psicanalítica se torna estéril.

Para os autores, mais importante que fazer um novo sistema é desterritorializar os já existentes, soltá-los no cosmo, abrir o agenciamento a uma força cósmica, com a prudência necessária para que a força cósmica não se torne má. "Só que nunca estamos seguros de ser suficientemente fortes, pois não temos o sistema, temos apenas linhas e movimentos" (Deleuze e Guattari, [1980] 1997, p. 170).

Deleuze e Guattari consideram que as formas essenciais ou substanciais foram criticadas de maneiras muito diversas. No entanto, foi Espinosa quem procedeu radicalmente, chegando a elementos que não têm mais nem forma nem função, que se distinguem apenas pelo grau de movimento e de repouso, de lentidão e de velo- cidade. Dependendo do agenciamento em que entram, esses elementos pertencem a este ou àquele indivíduo, que pode ele mesmo ser parte de outro indivíduo numa outra indivíduo é uma multiplicidade infinita, e a natureza inteira, uma multiplicidade de multiplicidades perfeitamente individuada. O plano de consistência da natureza é como uma imensa máquina abstrata, cujas peças são os agenciamentos ou os indivíduos diversos que agrupam, cada um, uma infinidade de partículas. Trata-se de um plano de extensão, de imanência ou univocidade que se impõe à analogia dos pensamentos estruturais ou de tendência representacional.

A questão deixa de ser a da organização, a dos órgãos e das funções, enfim, de um plano transcendente que impõe a lógica das relações analógicas e de tipos de desenvolvimento divergentes, e passa a se tratar das composições. Parece-nos que a psicanálise teria muito a ganhar se focalizasse mais a questão das composições e das experimentações, em vez de rebater tudo sobre representações familiares e sobre a questão dos limites.

A pergunta espinosista sobre o que pode um corpo também seria bastante útil à prática psicanalítica, já que devolveria a liberdade que as teorias estruturais retiraram do corpo. Ela possibilitaria um pensamento ético que procura saber quais são os afetos de um corpo, e como em cada caso eles podem ou não se compor com os afetos de outro corpo, seja para destruí-lo ou ser destruído por ele, para trocar com esse outro corpo ações e paixões ou para compor com ele um corpo mais potente, saber sobre seus limites, tamanhos internos, ao invés de se submeter a categorias universais. Empreendimento infinito, já que podemos começar um plano de mil maneiras, assim como recompor e remanejar o conjunto dos agenciamentos infinitas vezes.

Todo agenciamento em seu conjunto individuado é uma becceidade, uma individuação sem sujeito; tem-se a individuação de um dia, de uma estação, de um enxame. Trata-se de um plano inteiramente distinto daquele das formas. Sem dúvida, seria um desafio para a psicanálise clássica se inserir nesse movimento infinito, nesse jogo nômade de individuações que lançaria as mais pesadas dúvidas sobre uma teoria que muitas vezes pensa o ser de forma estática.

A temporalidade no plano de imanência também é outra. Aion é o tempo indefinido do acontecimento, linha flutuante que só conhece velocidades, ao contrário de Cronos, o tempo da medida, que fixa as coisas e as pessoas, desenvolve uma forma e determina um sujeito.

O uso da linguagem também é diferente, pois o plano de consistência só tem por conteúdo hecceidades, uma vez que ele se liberou das significâncias formais e das subjetivações pessoais. Portanto, sua semiótica é composta sobretudo de nomes próprios, de verbos no infinitivo e de artigos ou de pronomes indefinidos. $\mathrm{O}$ verbo no infinitivo não é indeterminado - ele exprime o tempo flutuante próprio do Aion, tempo do devir, que enuncia apenas velocidades e lentidões relativas. $\mathrm{O}$ nome próprio não indica um sujeito - indica sim um devir, um acontecimento, uma hecceidade. O pronome indefinido, também, de forma alguma é indeterminado: nada lhe falta quando introduz hecceidades, acontecimentos cuja individuação não passa por uma forma, um sujeito.

Deleuze e Guattari levantam a hipótese de que talvez existam dois planos, ou seja, duas maneiras de conceber o plano. O plano pode ser um princípio oculto que dá a ver aquilo que se vê, mas ele próprio não é dado - é por natureza oculto. Aí poderíamos incluir o plano em que se desenvolve a teoria psicanalítica mais tradicional. Esse plano concerne ao desenvolvimento das formas que ocultam uma estrutura necessária - a formação dos sujeitos com seus significantes secretos - e possui uma dimensão suplementar àquilo que ele dá. Este é o plano de transcendência, que estabelece a lógica das analogias e das estruturas.

Existe também uma outra concepção do plano: outro plano, onde não há mais desenvolvimento de formas, nem sujeitos ou estrutura de 
gênese. O plano de imanência, que se opõe ao plano de transcendência, é um plano de univocidade - ele jamais apresenta uma dimensão suplementar àquilo que se passa por ele. As dimensões do plano de imanência não param de crescer com aquilo que se passa nele. Portanto, os autores afirmam que é um plano de proliferação, de povoamento, de contágio, plano onde a forma não para de ser dissolvida para liberar tempos e velocidades. Plano de experimentação contra toda interpretação, e lugar onde uma nova modalidade de psicanálise poderia ser criada. Os autores nos lembram que, necessariamente, em um plano onde não há organização, desenvolvimento ou formação, e sim transmutações, o fracasso vai estar sempre presente, pois faz parte integrante do plano de imanência.

Segundo os autores dos Mil Platôs, não paramos de passar de um plano ao outro, por graus insensíveis e sem sabê-lo. O plano de imanência implica uma desestratificação de toda a natureza: ele é o $\mathrm{CsO}$, movimentos desterritorializados. No entanto, esse plano não pré-existe aos movimentos de desterritorialização que o desenvolvem, aos devires que o compõem. Assim como o plano de transcendência não para de trabalhar sobre o plano de consistência, tentando sempre impedir as linhas de fuga e interromper os movimentos de desterritorializacão, o plano de consistência também não para de se extrair do plano de organização, de levar partículas a fugirem para fora dos estratos, de embaralhar as formas.

Os autores enfatizam novamente quanta prudência é necessária para que o plano de consistência não se torne um puro plano de abolição, de morte, ou de retorno ao indiferenciado, e se perguntam: até que ponto não será preciso guardar um mínimo de estratos, um mínimo de formas, um mínimo de sujeito para dele extrair materiais, afetos e agenciamentos?

Uma parte considerável da obra de Deleuze trata do problema da prática, de como podemos pôr em movimento as forças criativas e nos afastar das forças reativas que diminuem nossa potência de agir ao operar com um sistema limitativo.

No artigo "Imanência: uma vida" (2006), Deleuze faz uma distinção entre o transcendente e o campo transcendental. Ele define o campo transcendental como oposto a tudo o que constitui o mundo do sujeito e do objeto. Nesses termos, pode ser considerado como consciência a-subjetiva, impessoal, sem eu, campo que transcende todas as categorias que impõem limitações ao ser.

O campo transcendental é bastante diferente do transcendente. A consciência, quando produz um sujeito, aparece como "transcendente". A psicanálise, ao produzir o sujeito edípico neurótico ou o psicótico marginalizado, participa desse campo transcendente. Já o campo transcendental escapa à transcendência do sujeito e do objeto, e define-se como puro plano de imanência-imanência que não se relaciona com qualquer coisa capaz de contê-la.

Diremos da pura imanência que ela é UMA VIDA, e nada mais. Ela não é imanente à vida, mas a imanência que não está em nada mais é ela mesma uma vida. Uma vida é a imanência da imanência, a imanência absoluta: ela é completo poder, completa beatitude" (Deleuze, 2006, p. 385-386).

A imanência é uma vida, e o artigo indefinido é de importância fundamental. Serve como índice do transcendental, em que a vida do indivíduo deu lugar a uma vida impessoal e, no entanto, singular. É uma hecceidade que já não é individuação, mas singularização. Vida de pura imanência, neutra, para além do bem e do mal. A vida imanente de um homem que já não tem nome, mas que não se confunde com qualquer outro.

Deleuze nos diz que uma vida singular dispensa toda individualidade, ou qualquer outra coisa que a individualize, que a categorize. $\mathrm{O}$ autor dá o exemplo das crianças pequenas, que se parecem todas e não têm individualidade, mas singularidades, um sorriso, um gesto. Elas são atravessadas por uma vida imanente que é pura potência.

A psicanálise clássica parece transformar todos os acontecimentos e os seres em formas transcendentes que espera aplicar a tudo e a todos. Desse modo, para Deleuze, a psicanálise tradicional se funda num plano de transcendência e participa de uma política de repressão mais do que de uma política de liberação do ser e do pensamento. No entanto, Deleuze é um pensador critico mas também afirmativo. Daí podermos inferir que ele acredita na possibilidade, na capacidade criativa de uma reformulação e de uma positivação da psicanálise, supondo que ela própria disporia de elementos para tal empreitada. 
Deleuze, no texto $O$ que as crianças diæem ([1993] 1997), afirma sua posição de acreditar numa concepção cartográfica da vida e do inconsciente, que já não lida mais com as categorias de pessoas e objetos, mas com trajetos e devires. "A criança não para de dizer o que faz ou tenta fazer: explorar os meios, por trajetos dinâmicos, e traçar o mapa correspondente" (Deleuze, 1997, p. 73). Dessa forma, o indefinido se torna a determinação do devir, e o impessoal revela as singularidades.

Para finalizar, consideramos possível vincular esse processo de desidentificação de estratos dominantes com a ideia deleuziana sobre o que dizem as crianças, e indicar que esse parece ser o caminho para ir atrás do super-homem nietzschiano - aquele que fala da superação do homem, e que leva a um gesto afirmativo de dizer sim ao mundo tal como ele é, escapando da dialética, da representação, do ressentimento, e colocando-se diante da imediaticidade do devir, atingindo uma espécie de grande saúde que somente algo da ordem do sobre-humano poderia alcançar. $\mathrm{O}$ além do homem traz uma nova maneira de sentir, uma nova maneira de pensar - traz a radicalidade do pensamento de Nietzsche, com um sentido de superação e reinvenção do homem, e não sua adaptação.

\section{Referências}

Artaud, A. (2004). Pour en finir avec le jugement de dieu. Oeuvres quatro. Paris: Gallimard. (Publicado originalmente em 1948).

Deleuze, G. (1988). Diferença e repetição. Rio de Janeiro: Graal. (Publicado originalmente em 1968).

Deleuze, G. (1997). Crítica e clínica. São Paulo: Ed. 34.

Deleuze, G. (2006) The interpretation of utterances. In: Deleuze, G. Two regimes of madness. Texts and interviews 1975-1995 (pp. 385-386). New York: Semiotext(e).

Deleuze, G., \& Guattari, F. (1996) Mil Platôs: Vol. 3. Capitalismo e esquizofrenia. Rio de Janeiro: Ed. 34. (Publicado originalmente em 1980).

Deleuze, G., \& Guattari, F. (1997) Mil Platôs: Vol. 4. Capitalismo e esquizofrenia. Rio de Janeiro: Ed. 34. (Publicado originalmente em 1980).
Holland, E. (1999). Deleuze e Guattari's Anti-Oedipus. Londres: Routledge.

Recebido: 25/05/2009

Received: 05/25/2009

Aprovado: $15 / 03 / 2010$

Approved: 03/15/2010 